\title{
Contradições no/do cotidiano escolar: professores e alunos com deficiência diante do ensino na diversidade
}

\author{
Ana Paula de Freitas ${ }^{*}$ \\ Maria Inês Bacellar Monteiro** \\ Evani Andreatta Amaral Camargo***
}

\begin{abstract}
Resumo
A partir do referencial teórico histórico-cultural do desenvolvimento humano e de conceitos bakhtinianos de interação dialógica e do ato responsável, temos como objetivos neste texto compreender como professores de alunos com deficiência intelectual têm se posicionado diante do ensino na diversidade, que concepções sobre deficiência orientam seu fazer docente e como avaliam seu trabalho com estes alunos. Para responder a tais questões, analisamos encontros entre professores do Ensino Fundamental II e pesquisadores vinculados a instituições de ensino superior, em um processo de reuniões colaborativas. Foram trazidos recortes dessas falas docentes, construídos em dois episódios. Como resultados, compreendemos que os educadores têm conhecimento do que lhes cabe ensinar, no entanto, revelam o conflito em que vivem, trazendo as marcas de uma construção social da deficiência. Avaliamos que os encontros na perspectiva colaborativa podem possibilitar reflexões que permitam aos professores pensar sobre suas ações pedagógicas no ensino da diversidade.

Palavras-chave: Diversidade. Perspectiva Histórico-Cultural. Educação Especial. Deficiência Intelectual. Cotidiano Escolar.
\end{abstract}

\section{Contradictions in/from school life: teachers and students with disabilities in face of diversity teaching}

\begin{abstract}
Based on the cultural historical theory of human development and on Bakhtinian concepts of dialogic interaction and responsible act, it is our aim to understand how teachers of students with intellectual disabilities see education in diversity, what conceptions of disability guide their teaching and how they evaluate their work with these students. To answer these questions, we analyzed meetings between Secondary Schoolteachers and researchers linked to institutions of higher education in a process of collaborative meetings. We herein present clippings of the teachers' speeches, built in two episodes. As a result, we understand that educators are aware of what they must teach, however, they reveal the conflict in which they live, bringing the marks of asocial construction of disability. We conclude that meetings in a collaborative perspective can produce reflections that allow teachers to think about their educational actions in the teaching of diversity.

Keywords: Diversity. Cultural Historical Perspective. Special Education. Intellectual Disabilities. School life.
\end{abstract}

\section{Introdução}

O contato com professores da educação básica de escolas públicas que recebem em suas salas de aula uma diversidade de alunos, como previsto nas políticas e documentos educacionais (BRASIL, 1996; 2014), entre eles, os com deficiência, têm nos permitido conhecer as profundas contradições que marcam o cotidiano escolar e o fazer docente. Se, por um lado, encontramos professores preocupados com o ensino para a diversidade, buscando meios de ensinar a todos os alunos, por outro lado, nos deparamos com concepções docentes sobre a deficiência e sobre o ensino de alunos com deficiência que acabam por afastar qualquer possibilidade de acesso ao conhecimento escolar para esses alunos.

Neste texto, a partir da análise de fragmentos dos dizeres docentes durante os encontros de formação continuada que temos realizado com eles, na perspectiva da pesquisa colaborativa (IBIAPINA, 2008), pretendemos apontar e analisar tais contradições, tendo em vista as ideias que historicamente circulam no contexto sociocultural sobre o ensino para pessoas com deficiência intelectual e, a partir daí, discutir perspectivas para a prática educativa, considerando a diversidade de alunos que têm acesso à escola, focalizando especialmente os alunos com deficiência.

*Universidade São Francisco. Endereço eletrônico: freitas.apde@gmail.com

**Universidade Metodista de Piracicaba. Endereço eletrônico: monteirobim@gmail.com

***Centro Universitário Moura Lacerda. Endereço eletrônico: evaniamaral@ gmail.com 
Tomamos como referência teórica a perspectiva histórico-cultural do desenvolvimento humano (VIGOTSKI, 1995; 2000). Vigotski fundamenta-se no materialismo histórico e dialético (MARX; ENGELS, 2007), que busca a compreensão da história e da consciência humana e, para isto, focaliza a produção e a reprodução das condições de existência dos homens, atreladas às relações dos homens com a natureza e com suas formas de organização social. Para o autor, a palavra história pode ser compreendida de dois modos: como uma abordagem dialética, isto é, qualquer coisa tem uma história e como história no sentido próprio do termo, ou seja, a história do homem. E, desta forma, explicita sua tese sobre o desenvolvimento psíquico:

As funções superiores diferentemente das inferiores, no seu desenvolvimento, são subordinadas às regularidades históricas [...] Toda a peculiaridade do psiquismo do homem está em que nele são unidas (síntese) uma e outra história (evolução + história) (VIGOTSKI, 2000, p. 23).

$\mathrm{O}$ autor atribui às condições sociais concretas, o desenvolvimento cultural dos homens. Ou seja, o homem, ao nascer é dotado de um aparato biológico (funções naturais/elementares), todavia, é a imersão em um mundo social, nas relações sociais, que faz com que o homem se aproprie e desenvolva suas funções psíquicas (atenção voluntária, imaginação criadora, memória lógica, vontade, elaboração conceitual, linguagem etc.). Pino (2000, p. 51) argumenta que o desenvolvimento humano sendo cultural, portanto, histórico, expressa "o longo processo de transformação que o homem opera na natureza e nele mesmo como parte desta natureza. Isso faz do homem o artífice de si mesmo". Para Vigotski (1997, 2000), não há possibilidades de desenvolvimento humano fora do contexto social, das relações sociais entre os homens. Mas esta relação entre o homem e o mundo que o rodeia não é direta, é mediada por instrumentos e signos criados pelo homem.

A mediação semiótica é um dos conceitos centrais da teoria histórico-cultural para a compreensão do processo de internalização processo pelo qual as funções psicológicas superiores (plano social/cultural) são apropriadas pelos indivíduos e se tornam internas (plano individual). Nesta perspectiva, os instrumentos técnico-semióticos (criação da cultura humana) são os mediadores que possibilitam aos homens transformar e conhecer o mundo, comunicar experiências e desenvolver novas funções psíquicas (PINO, 1991, 2000).

Como o desenvolvimento humano tem origem social, é possível afirmar que o aparato biológico, por si, não define as possibilidades de uma pessoa se desenvolver, pois, tal desenvolvimento está arraigado às condições materiais de existência humana. Ter isto em vista é crucial para se compreender as possibilidades de funcionamento psíquico de pessoas que possuem comprometimento nas funções elementares (biológicas), como é o caso dos alunos com deficiência intelectual.

Amaral (1995) discute o conceito de deficiência e como este vai sendo constituído no decorrer da história. Conforme a autora, sobretudo na Antiguidade e Idade Média, a concepção da deficiência está ligada ao conceito de marginalização. Termos como monstros, indivíduos nocivos, defeituosos são comuns à época. Nos séculos XVIII e XIX, noções assistencialistas se fazem presentes, como também abordagens educacionais e médicas. Profissionais como Pinel, Itard, Down e Froebel se debruçam na compreensão da deficiência, sobretudo, a intelectual. De um modo geral, o século XIX assinala o período da superação da visão da deficiência como doença e o início do seu entendimento como condição ou estado. A primeira metade do século XX é marcada pela ênfase orgânica em relação aos fatores etiológicos da deficiência. Mas, sobretudo, com o interesse da psicologia pela temática, as preocupações educacionais se tornam cada vez mais manifestas. Surgem, nesta época, os testes de inteligência, tais como, os de Binet. É somente a partir da segunda metade do século XX que começam a despontar visões menos preconceituosas em relação à deficiência e às pessoas com deficiência. Porém, ressalta Amaral (1995, p. 53), tais transformações ocorrem mais no âmbito "oficial", pois "extra-oficialmente", os diferentes modos de se conceber a deficiência ainda circulam pela sociedade e assim, "continuamos a ver diferentes práticas e políticas públicas" que os rotulam e os excluem.

Carvalho (2006) constata que nas últimas décadas há uma ampliação das possibilidades de desenvolvimento dessa população em decorrência de fatores como avanços médicos (campos da genética, da bioquímica e da neuropsicologia, por 
exemplo), melhorias no campo da saúde e, consequentemente, melhores oportunidades de inserção social. Entretanto, no Brasil, as conquistas notadas na transformação das relações sociais que envolvem as pessoas com deficiência abrangem um percentual mínimo dessa população e são assumidas como impossibilidades por muitas famílias e profissionais. Segundo a autora, isto é um reflexo da maneira como a sociedade concebe a deficiência.

Sobre a concepção da deficiência, Amaral (1995) propõe pensá-la não mais e tão somente como desvio ou anormalidade, mas como a expressão da diversidade da natureza e da condição humana. A autora discute a questão a partir dos conceitos de deficiência, incapacidade e desvantagem. Explica que a deficiência diz respeito a um dano ou anormalidade que reflete perturbações a nível orgânico e a incapacidade reflete as consequências das deficiências em termos de restrição de execução. Ambas afirmam uma condição concreta da realidade e são consideradas deficiência primária por englobarem os fatores intrínsecos, as limitações em si. Por sua vez, a desvantagem diz respeito aos prejuízos que uma pessoa apresenta devido à sua deficiência e incapacidade. Trata-se de um conceito relativo, pois está ligado aos valores, normas e padrões do grupo no qual a pessoa com deficiência está inserida e refere-se à deficiência secundária, sobre a qual a autora afirma que é "ligada à leitura social que dela é feita. Incluem-se aqui as significações afetivas, emocionais, intelectuais e sociais que o grupo atribui a dada diferença" (AMARAL, 1995, p. 68).

Sendo assim, as reações sociais dependem das especificidades da deficiência (tipo, visibilidade etc.) e nem sempre são da mesma forma. Neste sentido, para a autora há uma construção social da deficiência que se dá por meio de estigmas e preconceitos sociais constituídos nas relações sociais, uma vez que a sociedade em determinados contextos histórico-sociais determina o que é ideal, o que é esperado, o que está dentro da norma.

Como alternativa à construção social da deficiência, Amaral (1995, p. 150) afirma a necessidade de ressignificação da diferença/deficiência, ou seja, é preciso ir ao encontro de

[...] relações despidas de hierarquia entre aqueles que são diferentes/deficientes e os que não o são [...] relações que impliquem em encontro de identidades - relações que serão então, e só então, fruto de uma verdadeira e profícua re-significação da diferença.

No cenário brasileiro, no âmbito educacional, as teorias psicológicas têm trazido contribuições à compreensão da deficiência, sobretudo, da deficiência intelectual. São diferentes os modos de se conceber o psiquismo humano e de compreender os processos de desenvolvimento e aprendizagem, o que determina distintas ações pedagógicas.

Conforme explicita Carvalho (2006), o contexto pedagógico é marcado por diferentes enfoques psicológicos sem que fiquem claras as contradições existentes entre as abordagens de desenvolvimento humano que os fundamentam. Assim, no século XX, predomina o ideário inatistamaturacionista que compreende o desenvolvimento da inteligência como um conjunto de capacidades inatas e biologicamente determinadas. Nesta visão, entende-se que a pessoa com deficiência intelectual tem um comprometimento estático e irreversível.

A teoria comportamental busca um modelo de regularidade e progressão dos processos evolutivos, com a ideia de determinação ambiental do desenvolvimento humano e a consequente suposição de controle das mais diversas formas de manifestação do comportamento. No contexto da educação especial, a não resposta dos alunos com deficiência aos estímulos externos e a não apresentação de comportamentos esperados leva ao treinamento para a aquisição de habilidades, caminhando passo a passo, do mais simples ao mais complexo.

No enfoque cognitivista (ideário construtivista), a deficiência intelectual é explicada por estágios de desenvolvimento não alcançados e, portanto, por estruturas cognitivas deficitárias ou disfuncionais. A falta de experiências do sujeito com o meio ambiente (meio social) ou problemas orgânicos justificam o déficit intelectual.

As teorias psicológicas circulantes, portanto, compreendem a deficiência e a pessoa com deficiência pelo olhar do déficit e da negação. Segundo Carvalho (2006), no Brasil, no início do século $\mathrm{XX}$, o enfoque psicométrico se estabelece como forma de diagnosticar a existência do déficit intelectual e, principalmente, definir a possibilidade ou não da criança com deficiência ser educada e, ainda hoje, no nosso sistema educacional, o modelo psicométrico é o prevalente na avaliação e diagnóstico da deficiência nos campos da psicologia e da pedagogia. 
Consideramos oportuno, neste momento, retomar algumas das proposições de Vigotski (1995, 1997) sobre as possibilidades de desenvolvimento de pessoas com deficiência, tendo em vista que o autor enuncia um modo de conceber a deficiência que se orienta para um enfoque prospectivo em oposição a uma visão do déficit intelectual como biologicamente definido, irreversível e passível de mensuração. Para o autor, as possibilidades de elaboração psíquica superior emergem e se realizam continuamente nas relações dinâmicas em que a pessoa está imersa, nas práticas socioculturais. Sendo assim, as condições orgânicas não são determinantes do desenvolvimento humano. Os comportamentos de ordem biológica/orgânica são reconhecidos como funções elementares. Mas, nesta linha de argumentação, compreendemos que as funções psicológicas superiores, típicas da espécie humana, não estão dadas no indivíduo. Elas se originam e se constituem a partir das/nas relações sociais mediadas por instrumentos técnicosemióticos. Deste modo, afirmar que a pessoa com deficiência tem alterações no funcionamento mental superior e que esta é uma característica inerente à deficiência é um equívoco, pois

[...] o desenvolvimento psicológico resulta da síntese entre os aspectos orgânicos (biológicos) e os aspectos psicossociais em jogo na vida do sujeito [...] nesse processo é precisamente a indeterminação genética das ações humanas que abre a possibilidade de sua transformação, da diversidade de suas formas de realização nas interações sociais (CARVALHO, 2006, p. 33).

Afirmamos no início deste texto que o cotidiano escolar está marcado por contradições entre as concepções dos docentes sobre a deficiência e as possibilidades de aprendizagem e de desenvolvimento de seus alunos com deficiência e o sentimento de responsabilidade que estes possuem em relação ao seu papel como professores no que se refere ao ensino desses alunos. Desta maneira, consideramos pertinente realizar algumas reflexões sobre essa questão trazendo à tona conceitos de Bakhtin $(1995,2012)$ que nos orientam para a compreensão das relações intersubjetivas que ocorrem nas situações concretas vividas por alunos e professores no contexto escolar.

Geraldi (2013) reflete sobre as implicações do pensamento de Bakhtin para o âmbito educacional e esclarece que não há na obra bakhtiniana referência explícita à educação escolar, todavia, por meio dos seus textos, Bakhtin teria muito a dizer aos educadores. Deste modo, Geraldi (2013, p. 15) afirma

Assim, nos campos de estudos de Bakhtin, está sempre presente o outro como ser vivo e falante. E este é precisamente o mesmo princípio fundante da ação educativa, ainda que às vezes esquecido porque tão profundamente enraizado: não há educação fora da relação entre o eu e o outro. E tal como em Bakhtin, desta relação com a alteridade nenhum dos dois sai inalterado, ninguém sai como entrou. Se no mundo da vida não saímos de um diálogo sem com ele nos enriquecermos, também nos processos educativos professor e aluno saem diferentes, porque nessa relação ambos aprendem.

Para Bakhtin (1995, p. 113), um caminho possível de aproximação entre o eu e o outro é o diálogo; por meio da palavra o eu e o outro se encontram, "ela constitui o produto da interação do locutor e do ouvinte. Toda palavra serve de expressão a um em relação ao outro. Através da palavra, defino-me em relação ao outro, isto é, em última análise, em relação à coletividade." Deste modo, podemos compreender que a relação professor e aluno está repleta de diálogo. Mas, é preciso esclarecer que para Bakhtin (1995), esta relação dialógica não diz respeito unicamente à interação verbal face a face, mas a toda comunicação verbal, determinada pelo contexto social mais amplo (vida cotidiana, conhecimento, arte, política etc.).

Sendo assim, no cotidiano escolar, a dinâmica dialógica se faz presente nos processos de intersubjetividade e está permeada pela diversidade de alunos e vivências que cada um traz, pelos conhecimentos espontâneos e científicos envoltos na prática pedagógica, pelas concepções e experiências docentes, pelos documentos políticos que determinam e orientam os modos de agir dos educadores, entre outros.

Ainda no que se refere à relação constitutiva entre o eu e o outro (princípio da alteridade) encontramos nos estudos de Bakhtin (2012) sobre ética e responsabilidade, argumentos centrais para a reflexão sobre o papel docente e sua prática. $\mathrm{O}$ autor compreende que o processo de 
constituição humana não tem fim, somos sujeitos incompletos e mutáveis e é sempre o outro que nos dá uma completude provisória e, assim, Bakhtin (2012) funda "o ato responsivo justamente na responsabilidade para com o outro a que responde e aos outros que responderão ao ato praticado" (GERALDI, 2013, p. 14).

Para Bakhtin (2012), nesta relação eu-outro, o eu ocupa um lugar único, irrepetível e impenetrável para o outro. No tempo singular e no tempo presente, nenhuma outra pessoa jamais esteve, assim, o existir é singular e obrigatório. Por isso, o autor traz o conceito do 'não-álibi' no existir. Afirma que "tudo o que pode ser feito por mim não poderá nunca ser feito por ninguém mais, nunca" (BAKHTIN, 2012, p. 96). É o 'não-álibi' da existência que está na base do dever concreto e único do ato. Deste modo, o que fundamenta a consciência responsável é o reconhecimento real que o sujeito possui de sua participação no ato como evento singular e sobre isto enuncia "a vida pode ser compreendida pela consciência somente na responsabilidade concreta [...] Separada da responsabilidade, a vida não pode ter uma filosofia; ela seria, por princípio, fortuita e privada de fundamentos" (BAKHTIN, 2012, p. 117).

Consideramos que os conceitos de responsabilidade e não-álibi nos auxiliam a refletir sobre o papel do professor na relação com seus alunos. No contexto escolar, o professor, em sua singularidade é responsável diante do seu aluno e, do mesmo modo, o aluno, também único, responde pelos seus atos, durante as aulas.

Tais reflexões podem ser deslocadas para se pensar no trabalho docente em relação ao aluno com deficiência, no contexto das políticas de inclusão escolar e é, deste lugar, que buscamos problematizar a questão. Estudos apontam (FERREIRA, 2006; DAINEZ, 2009; VIEIRA, 2013) que o aluno com deficiência intelectual não está tendo acesso ao conhecimento escolar; os professores, embora tenham clareza do seu papel de ensinar, sentem-se despreparados e inseguros para esta tarefa (SILVA, 2015).

A partir destas considerações teóricas, temos como objetivo neste texto, compreender como os professores de alunos com deficiência têm se posicionado frente ao ensino na diversidade, que concepções sobre deficiência orientam seu fazer docente e como avaliam seu trabalho frente ao aluno deficiente. Por fim, pretendemos apontar caminhos para o ensino na diversidade, tendo como princípio que diferentes experiências humanas enriquecem o processo de se tornar humano.

\section{Contextualização da pesquisa}

O caráter histórico e dialético da perspectiva histórico-cultural possibilita compreendermos o método de Vigotski (1995) como processual e dinâmico. Assim, a ênfase é dada à história dos processos como movimento dialético, assinalado por contradições, concordâncias, isto é, tensões que são circunscritas à dinâmica do funcionamento intersubjetivo.

Diante disso, supomos que esta pode ser uma forma promissora de análise. Tendo isto em vista, temos realizado encontros de formação continuada com professores de uma escola pública pertencente à diretoria de ensino estadual de uma cidade do interior paulista. Esta escola atende aos alunos do Ensino Fundamental II e Ensino Médio. Os encontros de formação, na perspectiva da pesquisa colaborativa, estão sendo realizados na própria escola, quinzenalmente, com duração de duas horas e tiveram início em março de 2015.

Participam destes encontros duas pesquisadoras vinculadas a programas de pósgraduação em Educação de universidades privadas, dois alunos (um bolsista de iniciação científica e uma mestranda), 15 docentes da escola de diferentes áreas do conhecimento (língua portuguesa, história, geografia, artes, biologia, matemática e educação física), bem como a diretora da escola. Em alguns encontros participam também a professora coordenadora do ensino fundamental II, a professora especialista, responsável pela sala de recurso (deficiência intelectual) e a coordenadora de educação especial da diretoria estadual de ensino.

Os registros dos encontros são realizados por meio de audiogravações e diário de campo. Para este texto, trazemos fragmentos de fala dos participantes que permitem discutir as contradições que marcam o fazer docente em relação ao trabalho com o aluno com deficiência intelectual. Nas análises da dinâmica dialógica que ocorre durante os encontros, focalizamos duas unidades centrais: a concepção dos docentes sobre a deficiência e a noção de responsabilidade docente.

\section{Responsabilidade docente e concepções de deficiência}

Episódio 1: Neste primeiro encontro do grupo, momento em que as pesquisadoras apresentam a proposta de realização do estudo para discutir 
possibilidades de ensino destes alunos, as docentes revelam às pesquisadoras suas concepções sobre o aluno com deficiência e suas preocupações em relação ao trabalho com este aluno.

Profa. $R$. (responsável pela sala de leitura): eu percebo que alguns alunos que frequentam a sala têm muita dificuldade, uma menina que me chama muito a atenção é a RA.

Dir. M.(diretora): Nossa, vocês deviam estudá-la. (risos)

Profa. R.: a RA., eu percebo ela, o problema não é que o professor não consegue alfabetizá-la, ela não se permite, porque ela é muito hiperativa, muito, muito, então, sei lá, porque é o caso de uma ritalina, uma consulta médica, sei lá, porque eu acho que se ela se concentrar ela consegue, mas ela é tão hiperativa, ela não consegue fazer nada, ela cai, ela levanta

Dir. M.: (risos) é uma coisa impressionante!

Profa. R.: ela fala errado[...]. Ela cutuca, ela faz, ela mexe no outro, aí ela se joga da cadeira, ela cai no chão, ela rola, aí ela vai mexer no outro...gente do céu!

Dir. M.: o pior de tudo é a família inteira, todos têm problemas, o pai, a mãe, o irmãozinho, todos têm problemas.

[...]

Profa R. (língua portuguesa): Diante de tudo isto, que todo mundo desabafou $e$ falou, trabalhar com estes alunos que tem necessidade que nem o D., você não tem como, é muita indisciplina, eu queria fazer alguma coisa para ele, às vezes, a gente se sente mal, aí que eu falo, você pega um aluno que é melhor aqui para sentar do lado dele e ajudá-lo, eu queria fazer alguma coisa.

Dir.M.: Eu pergunto, como vai fazer uma coisa no primeiro ano do ensino médio se ele não sabe ler e escrever?

Profa.R.: Mas, o D., ele tenta, né?

Observando este episódio destacamos a ideia trazida pela professora R. (responsável pela sala de leitura) de que o problema da não aprendizagem está no aluno. Nos dizeres desta professora, RA., aluna identificada pelos docentes como tendo deficiência intelectual (sem diagnóstico comprovado) não está alfabetizada porque "ela não se permite", é muito hiperativa e precisaria de um tratamento medicamentoso.

Iniciamos a análise, retomando a noção de concepção social de deficiência discutida por Amaral (1995). A aluna RA. não está aprendendo, apresenta, na visão das educadoras, comportamentos inadequados e, portanto, não está dentro da norma, do modelo ideal previsto pela sociedade. Sendo assim, RA., na relação com os professores da escola - pelo olhar do outro (BAKTHIN, 2012), vai se constituindo como uma aluna com deficiência intelectual. Esta concepção que compreende a pessoa com deficiência como alguém incapaz e com limites, é fruto da história de preconceitos e estigmas que marcou os sujeitos com deficiência ao longo da vida (AMARAL, 1995). Conforme aponta a autora, os campos médico e psicológico assumem a responsabilidade da educação dos deficientes e a ênfase recai sobre os aspectos orgânicos. Ainda na atualidade, o campo pedagógico é influenciado por essa visão. Compreendemos, portanto, que as concepções das educadoras sobre a aluna RA. são construídas socialmente nestes modos de se conceber a deficiência que circulam nas relações sociais.

A professora $\mathrm{R}$. e a diretora $\mathrm{M}$. revelam uma concepção de aprendizagem fundamentada no ideário inatista-maturacionista, conforme apontado por Carvalho (2006). Nesta perspectiva, para que a aluna possa se desenvolver (neste caso, ser alfabetizada) ela precisa ter prontidão e habilidades para isto, tais como, querer aprender, ter atenção e concentração. Os dizeres da professora R. revelam que para ela, a aprendizagem é determinada pelo desenvolvimento e este depende unicamente de fatores internos ao sujeito. Ao colocar a questão desta forma, a professora, mesmo sem ter clareza disto, exclui o papel da escola e das experiências possíveis no contexto escolar como fundamentais para o processo de aprendizagem da aluna RA. A ênfase que a diretora $M$. dá aos aspectos familiares (todos na família tem problemas) é um indício de que ela também tem uma concepção de aprendizagem ligada aos fatores hereditários. As educadoras, portanto, focalizam os aspectos biológicos para explicarem a não aprendizagem da aluna.

Retomamos a tese enunciada por Vigotski (1997) sobre o desenvolvimento psíquico. Para o autor, funções tais como, a atenção voluntária, a concentração e a vontade, são funções psíquicas superiores, portanto, não estão prontas no indivíduo ao nascimento, mas são constituídas ao longo da 
vida, em processos sociais, mediados por instrumentos e signos. Entretanto, as educadoras parecem transformar funções que são sociais e historicamente construídas (vontade, atenção, interesse etc.) em funções biológicas (características inerentes à aluna, inatas, biológicas), ou seja, a uma doença (hiperatividade), o que leva R. a concluir que a aluna RA. precisa ser medicada.

A questão da medicalização no ambiente escolar surge ao final do século XIX, início do século XX, em função de ações de higienização do ambiente escolar, dando origem à Saúde Escolar (WERNER, 1995). As premissas de tais ações residiam na necessidade de educar as camadas populares, que viviam em situações insalubres e, portanto, com inúmeras doenças. Neste sentido, era preciso excluir da escola aqueles considerados fracos, doentes e que não aprendiam. Assim, os mecanismos biológicos no processo de aprendizagem foram enfatizados e os fatores sociais e pedagógicos deixaram de ser considerados para se compreender as causas da não aprendizagem de alunos. Segundo Werner (1995, p. 39), "essas tentativas de encontrar uma causa orgânica para o mau rendimento escolar vão dar margem à chamada medicalização do fracasso escolar".

Conforme apontam Moyses e Collares (2011),a medicalização dos processos pedagógicos constitui, ainda hoje, um dos problemas mais sérios a serem enfrentados pela educação brasileira e, assim, questões sociais são transformadas em biológicas e a diversidade de alunos que não encontra espaço para aprender no ambiente escolar passa a ser considerada como hiperativa e desatenta.

A análise do episódio nos possibilita também identificar nos dizeres da professora R., a noção do não-álibi da existência, como apontado por Bakhtin (2012). A professora, referindo-se ao aluno D., ao dizer "eu queria fazer alguma coisa para ele" está convocando para si a responsabilidade pelo ensino deste aluno. Seus dizeres são um indício de que ela é consciente de que é responsável pelo outro. Ela procura fazer algo, como por exemplo, colocar um aluno 'melhor' para fazer a atividade junto com ele. Todavia, sua fala é permeada pelas contradições e tensões do cotidiano escolar: alunos com deficiência têm limites, precisam ser tratados com medicamentos, ela quer que o aluno aprenda, sente-se mal em não ensinar.

Episódio 2: Neste encontro, as pesquisadoras propõem a leitura e a discussão de um texto que traz uma síntese de três concepções teóricas sobre aprendizagem e desenvolvimento, são elas: comportamental, cognitivista (construtivismo) e histórico-cultural. Após a leitura, o grupo discute sobre as (im)possibilidades de alunos com deficiência aprenderem na escola regular.

Pesq. I.: ... o conceito de aprendizagem e de desenvolvimento vão se diferenciar de um modelo teórico para um outro modelo. Quando a gente olha a prática, a gente vai estar impregnado dos modelos teóricos que nos constituem.

Profa. M.C. (história): Eu queria só destacar essa frase aqui, de esperar o amadurecimento. Eu acho que aí, na questão o amadurecimento, vem com as experiências que a gente proporciona a eles e constroem condições concretas que fazem ocorrer transformações. Muitas vezes eles chegam para a gente, sem nenhum conhecimento prévio, sem nenhuma, no caso sem nenhum ambiente que consegue estimular a vontade de aprender. Você pediu para a gente trazer o material, eu trouxe duas provas do C. e do L., dos gêmeos, eles escrevem muito pouco, são copistas, mas assim, como eu trabalhei com o vídeo, eu achei o vídeo fundamental para eles assimilarem algumas coisas, então quando eu pergunto para eles sobre a questão da extinção de espécies, no caso eu falei da extinção dos Dinossauro [...] o L., ele fala que veio uma bola, né? E matou todo mundo, foi aquela bola que ele lembrou da imagem do asteroide caindo aqui e também ele falou destas imagens aqui da evolução humana, aqui ele conseguiu fazer um link como vê o futuro...e a prova dele foi oral [...] o C.,ele já falou a questão do buraco negro, que também é um conceito astronômico avançado (risos).De onde que ele tirou esta informação do buraco negro? De algum lugar [...] Mas ele associou aquele evento astronômico também a esse (mostra o desenho) que não tem nada a ver, mas é alguma coisa, que ... ele fez um link. [...] lachei bem interessante, mesmo ele tendo dito buraco negro eu considerei porque é um termo que não se usa e para um aluno do $6^{\circ}$ ano, então...

Dir. M.: e esses daí são diagnosticados mesmo!

Profa. M.C.: são de fato diagnosticados[...] 
E nós aqui estamos tendo esse ano essa gama de alunos com essa condição, então é difícil, não é fácil, porque a gente tem que lembrar que eles têm um outro ritmo $e$ também, para atendê-los em sala de aula, às vezes a gente não consegue um tempo, as vezes eu acho... nossa eu devia ter falado tal coisa com ele, não fiz.

Pesq. I.: acho interessante uma coisa que ela traz aí. Primeiro você aponta a questão do amadurecimento, de repente você entender o desenvolvimento como um amadurecimento ou você entender o desenvolvimento como dependente daquilo que é concreto, das experiências concretas que o aluno apresenta em sala de aula, isso são maneiras de olhar diferentes, para a questão do desenvolvimento [...] e às vezes, a gente pode não ter isso bem claro, mas na hora em que você coloca a teoria com a prática próximos, que você faz a relação teoria e prática, você vê que isto advém da maneira de se olhar diferente, também teoricamente. Então, isso, foi importante você colocar isto, porque vai realmente marcar duas correntes teóricas diferentes...

Coord. Ed. Esp. A.C.: de uma certa forma ela já manifesta a concepção dela

Pesq. I.: Isso! Exatamente! Já tem certa essa concepção mais relacionada com essa concepção histórico-cultural que é uma concepção que enfatiza a importância das experiências vividas pelos alunos em sala de aula.

Profa. M.C.: eu acredito muito que o aluno tem que experienciar, tem que viver aquilo que ele está aprendendo, dentro da medida do possivel, com as ferramentas que a gente tem, a gente tenta fazer atividades que eles vivenciam aqui, para que ele internalize, senão a gente fica na questão da cópia e do decorar, né?

[...]

Iniciamos a análise focalizando a interação dialógica que ocorre no contexto do encontro de formação continuada. Bakhtin (1995, 2003) compreende que o diálogo é o caminho de aproximação entre o eu e o outro. E, é nesta relação entre o eu e o outro que Geraldi (2013) aponta a possibilidade de aprendizagem.

Deste modo, ao examinarmos o episódio, compreendemos que há diálogo ocorrendo em um contexto social mais amplo (permeado pelos conhecimentos compartilhados, pelas experiências de cada um, entre outros).

A partir da retomada por uma das pesquisadoras, da ideia presente no texto lido anteriormente pelo grupo, de que há maneiras diversas de se olhar para os conceitos de desenvolvimento e aprendizagem, M.C. procura refletir sobre sua prática e destaca seu entendimento de que "o amadurecimento vem com as experiências que a gente proporciona", o que demonstra que ela percebe que é preciso algo mais do que o aporte inato para o aluno se desenvolver, ou seja, sua fala revela indícios de um movimento de atrelar o desenvolvimento às relações de ensino significativas (SMOLKA, 2010).

Constatamos a alternância dos participantes no diálogo quando: complementam a fala do outro (Dir. M. ao complementar a fala da Profa. M.C.: "esses são diagnosticados mesmos"), concordam com o outro (Profa. M.C. - "são de fato diagnosticados"), instigam o outro a continuar a reflexão (Pesq. I.: “...são maneiras diferentes de olhar..."). Pretendemos destacar com isso que na dinâmica dialógica cada um participa com seus conhecimentos e concepções sobre a vida e, neste jogo dialógico há tensões e contradições, porque os sujeitos que dele participam são singulares, únicos.

Chamamos a atenção neste episódio para as contradições nos dizeres da professora M.C.. Embora considere que muitas vezes os alunos cheguem "sem nenhum conhecimento prévio", ela vai mostrando no relato da atividade desenvolvida com dois alunos L. e C. (ambos com deficiência intelectual) que eles trazem conceitos, como o de "buraco negro", que ela não sabe de onde vem.

A Professora M.C. demonstra saber sua condição de sujeito responsável (BAKHTIN, 2012), busca caminhos para fazer com que os alunos L. e C. participem da atividade proposta, se valendo de diferentes instrumentos: filme, desenho, relato oral. Tais recursos funcionam como instrumentos técnico-semióticos (PINO, 1991, 2000) que possibilitam aos alunos se transformarem, aprenderem e desenvolverem funções psíquicas superiores. De acordo com Vigotski (1997), a mediação semiótica é um conceito central para a compreensão do processo de apropriação dos conhecimentos socialmente partilhados.

Por outro lado, a professora M.C. tem dúvidas sobre o que faz e revela achar difícil trabalhar com estes alunos, pois, segundo ela, eles têm ritmos de aprendizagem diferentes e 
precisariam de um trabalho mais individualizado. Notamos, portanto, que as noções circulantes sobre possibilidades de trabalho pedagógico com alunos com deficiência (AMARAL, 1995; CARVALHO, 2006) estão também constituindo a professora e seu fazer docente.

$\mathrm{O}$ enunciado da pesquisadora sobre as concepções de aprendizagem e possibilidades de relacionar a teoria e a prática contribuem para que a docente reflita sobre suas ações e, assim, no processo de interlocução, a professora diz acreditar nos alunos e nas práticas educativas que está proporcionando a eles, buscando meios para os alunos vivenciarem os conhecimentos científicos que objetiva trabalhar.

\section{Perspectivas para a prática educativa}

O cotidiano escolar com suas tensões e conflitos, entre a busca de uma educação para todos e as possibilidades concretas de trabalho do professor, mostram a complexidade de uma real transformação das práticas escolares que atenda à diversidade e às necessidades individuais dos alunos.

Os alunos com deficiência constituem uma parcela importante da escola atual e suas peculiaridades demandam uma atenção especial para que possam ter acesso ao conhecimento.

Ensinar na diversidade não é uma tarefa fácil. Contudo, podemos visualizar possibilidades de ressignificação das concepções de deficiência que permeiam o cenário escolar, o que permitirá um olhar prospectivo para o ensino do aluno com deficiência.

Os educadores do grupo estudado não negam a responsabilidade que cabe a eles de ensinar, no entanto, revelam o conflito que vivem diariamente na escola. Trazem as marcas de uma construção social da deficiência pautada em estigmas e preconceitos sociais constituídos nas relações sociais.

No entanto, os encontros na perspectiva colaborativa podem possibilitar uma reflexão pautada em fundamentos teóricos que auxiliam os professores a pensar sobre suas ações pedagógicas e modos de se olhar para o aluno com deficiência, levando-os a encontrar novos caminhos para ensinar.

Sena relação pedagógica, a relação eu-outro é condição para a aprendizagem do aluno e do professor, então o olhar que o professor tem sobre o aluno e sobre seus processos de aprendizagem, é central para a transformação das práticas estabelecidas.

Para avançar na reflexão sobre caminhos para o ensino na diversidade, consideramos que é necessária uma mudança na concepção de deficiência, orientada para práticas sociais que valorizem a singularidade dos alunos e que as relações se deem sem uma hierarquia entre aqueles que são diferentes/deficientes e aqueles que não os são.

\section{Referências}

AMARAL, L. A. Conhecendo a deficiência (em companhia de Hércules). São Paulo: Robe Editorial, 1995.

BAKHTIN, M. Marxismo e Filosofia $d a$ Linguagem. $7^{\text {a }}$ ed. São Paulo: Hucitec, 1995.

BAKHITN, M. Estética da Criação Verbal. 4. ${ }^{\mathrm{a}}$ ed. São Paulo: Martins Fontes, 2003.

BAKHTIN, M. M. Para uma filosofia do ato responsável. $2^{\mathrm{a}}$ ed. São Carlos: Pedro e João Editores, 2012, p. 41-146.

BRASIL. Lei $n^{\circ}$ 9394, de 20 de dezembro de 1996. Estabelece as diretrizes e bases da educação nacional. Presidência da República. Casa Civil, Brasília, DF. Disponível em: http://www.planalto.g ov.br/CCIVIL_03/leis/L9394.htm. Acesso em: 23 jun. 2015.

BRASIL. Planejando a próxima década: conhecendo as 20 metas do Plano Nacional de Educação. Ministério da Educação. Secretaria de Articulação com os Sistemas de Ensino, 2014. Disponível em: http://pne.mec.gov.br/images/pdf/p ne_conhecendo_20_metas.pdf. Acesso em: 11 jun. 2015.

CARVALHO, M. de F. Conhecimento e vida na escola: convivendo com as diferenças. Campinas: Autores Associados. Ijuí: Editora Unijuí, 2006.

DAINEZ, D. A inclusão escolar de crianças com deficiência mental: focalizando a noção de compensação na abordagem histórico-cultural. Dissertação (Mestrado em Educação) PPGE em Educação da Faculdade de Ciências Humanas. Piracicaba: Universidade Metodista de Piracicaba, 2009. Disponível em: <https://www.unimep.b 
r/phpg/bibdig/pdfs/2006/THJXLGNYJXOD.pdf>. Acesso em: 12 jun 2015.

FERREIRA, M. C. C. Os movimentos possíveis e necessários para que uma escola faça a inclusão de alunos com necessidades educacionais especiais. In: JESUS, D. M.; BAPTISTA, C.R; VICTOR, S. L. (Orgs.). Pesquisa e educação especial: mapeando produções. Vitória: Edufes, 2006. p. 139-154.

GERALDI, J.W. Bakhtin tudo ou nada diz aos educadores: os educadores podem dizer muito com Bakhtin. In: FREITAS, M.T. de A. (org.) Educação, Arte e Vida em Bakhtin. Belo Horizonte: Autêntica, 2013, p. 11-28.

IBIAPINA, I.M.L.M. Pesquisa colaborativa: investigação, formação e produção de conhecimentos. Brasília: Líber Livro. 2008.

MARX. K; ENGELS, F. A ideologia alemã. São Paulo: Boitempo Editorial. Tradução Rubens Enderle, Nélio Schneider, Luciano Cavini Martorano, 2007.

MOYSÉS, M.A.A.; COLLARES, C.A.L. Revendo questões sobre a produção e a medicalização do fracasso escolar. In: VICTOR, S.L.; DRAGO, R.; CHICON, J.F. (orgs.) Educação Especial $e$ Educação Inclusiva: conhecimentos, experiências e formação. Araraquara: Junqueira\&Marin, 2011, p. $21-41$.

PINO, A. O conceito de mediação semiótica em Vygotsky e seu papel na explicação do psiquismo humano. Cadernos Cedes, no 24, 1991. p. 32-43.

PINO, A. O social e o cultural na obra de Lev S.
Vigotski. Educação \& Sociedade, ano XXI, n 71 , julho/2000, P. 45-78.

SILVA, F. P. A constituição do professor no contexto da educação inclusiva: reflexões sobre sua formação e prática. 2015. 95f. Dissertação (Mestrado em Educação) Programa de Mestrado do Centro Universitário Moura Lacerda, Ribeirão Preto, 2015.

SMOLKA, A. L. B. Ensinar e significar: as relações de ensino em questão ou das (não)coincidências nas relações de ensino. Em: Smolka, A. L. B. \& Nogueira, A. L. H. Questões de desenvolvimento humano: práticas e sentidos. Campinas, São Paulo: Mercado das Letras, 2010, p. 107 - 128.

VIEIRA, S. da S. P. A constituição do sujeito com deficiência intelectual: um estudo das práticas na escola pública. Dissertação (Mestrado em Educação) Programa de Pós Graduação em Educação da Universidade Metodista de Piracicaba, Piracicaba, 2013, 81f.

VIGOTSKI, L.S. Psicologia concreta do homem. Educação \& Sociedade, ano XXI, n ${ }^{\circ} 71$, julho/2000, p. 23-44.

VYGOTSKI, L.S. Obras Escogidas III: Problemas Del desarrollo de la psique. Madri: Visor. 1995.

VYGOTSKI, L.S. Obras Escogidas V: Fundamentos de defectología. Madri: Visor, 1997.

WERNER, J. Saúde e Educação. Rio de Janeiro: Gryphus, 2005. (Educação em Diálogo. v. 5.).

\section{Sobre as autoras:}

Ana Paula de Freitas é graduada em Fonoaudiologia pela Pontifícia Universidade Católica de Campinas (1989) e Doutora em Educação pela Universidade Estadual de Campinas (2001). É professora do Programa de PósGraduação em Educação da Universidade São Francisco.

Maria Inês Bacellar Monteiro é graduada em Fonoaudiologia pela Pontifícia Universidade Católica de Campinas (1978) e Doutora em Psicologia pela Universidade de São Paulo (1992). É professora do Programa de Pós-Graduação em Educação da Universidade Metodista de Piracicaba (UNIMEP).

Evani Andreatta Amaral Camargo é graduada em Fonoaudiologia pela Universidade Federal de São Paulo (1977) e Doutora em Educação pela Universidade Estadual de Campinas (2000). É professora do Programa de Pós-Graduação - Mestrado em Educação- do Centro Universitário Moura Lacerda.

Recebido em junho de 2015.

Aprovado em novembro de 2015. 